\title{
CONSISTÊNCIA do ÉDIPO NA PSICANÁLISE LACANIANA: SÍMBOLOS ZERO PARA O DESEJO
}

\author{
Léa Silveira Sales ${ }^{\star}$
}

\begin{abstract}
Resumo
Durante os anos 1950, predomina na obra lacaniana uma releitura da psicanálise feita a partir do estruturalismo que inverte a abordagem da noção de inconsciente, conferindo efetividade a algo que, antes, era desqualificado como noção "inerte e impensável". Nela, ganha relevo uma reinterpretação do Édipo cujos termos são claramente inspirados em Lévi-Strauss. O objetivo do artigo é, nesse sentido, esclarecer a função dos significantes Nome-do-Pai e falo como "símbolos zero" da estrutura que conforma o desejo. Veremos que o fato de essa função ser requerida pelo psicanalista é tributário da forma pela qual o antropólogo descreveu tal tipo de símbolos.
\end{abstract}

Palavras-chave: Estruturalismo. Psicanálise lacaniana. Édipo. Lévi-Strauss. Simbolo zero.

\section{OEDIPUS CONSISTENCY IN LACANIAN PSYCHOANALYSIS:}

\section{ZERO SYMBOLS FOR DESIRE}

\begin{abstract}
During the 50's, it prevails in Lacan's work a structuralist interpretation of psychoanalysis which inverts the approaching of the unconscious, assigning effectiveness to something that was formerly disqualified as "inert and unthinkable". In this context, it gains relief a re-reading of the Oedipus complex whose terms are clearly inspired in Lévi-Strauss. The purpose of this paper is to shed some light upon the function fulfilled by the signifiers "Name-of-the-Father" and "phallus" as "zero symbols" of the structure of desire. The way such kind of symbols were described by the anthropologist reveals why this function was requested by the psychoanalyst.
\end{abstract}

Keywords: Structuralism. Lacanian Psychoanalysis. Oedipus. Lévi-Strauss. Zero symbol.

\footnotetext{
^ Aluna do doutorado em Filosofia da Universidade Federal de São Carlos e bolsista CAPES. Endereço: Universidade Federal de São Carlos, Centro de Educação e Ciências Humanas. Rodovia Washington Luís, km 235 - Monjolinho. CEP: 13565-905 - São Carlos, SP - Brasil. E-mail: lea_silveira@uol.com.br
} 
A aplicação da estrutura à psicanálise é a responsável pelo fato de Lacan passar a admitir a universalidade do Édipo, antes visto sob uma perspectiva sociológica. No texto sobre os complexos familiares, voltado para a historicidade das formações sociais, Lacan, sem elementos para sustentar essa universalidade fora do domínio da biologia e apoiado nos estudos de Malinowski, entende o Édipo como um drama que deve ser circunscrito ao seio do ambiente no qual foi descoberto, configurando a determinação social específica do homem moderno e da família conjugal. ${ }^{1}$

Com a leitura estruturalista, o Édipo deixa de ser uma cena da família burguesa para dispor - em termos das relações primárias de passagem de um vínculo dual para as possibilidades metonímicas do desejo - o paradigma da entrada do ser humano na linguagem. A obra de Lévi-Strauss pavimenta o caminho não apenas para a admissão da operacionalidade do inconsciente mediante a própria noção de estrutura, ${ }^{2}$ como também para a hipótese de que sua incidência mesma requer a presença de uma Lei restritiva no campo sexual. Quando defende a proibição do incesto como conseqüência necessária das trocas sociais em qualquer sistema de parentesco - seja ele de troca restrita ou generalizada - e fenômeno de ligação/separação entre natureza e cultura, ${ }^{3}$ provê o ponto de partida para a colocação de uma questão essencialmente psicanalítica: como pensar a inscrição dessa Lei no sujeito e a produção de suas conseqüências? Além disso, tendo em vista o que Freud dissera a respeito do "complexo nuclear das neuroses", qual o ganho teórico que pode ser retirado de diretrizes que transportam a questão para um nível diferente do psicobiológico ou social?

Para Lévi-Strauss, a estrutura é, "grosso modo", um conjunto de leis que operam pela combinação sincrônica de pares de significantes entendidos como seus elementos constitutivos. A ela é atribuída a função de responder pela explicação do fenômeno ou da ordem da aparência e, à sua luz, supõe-se que os termos últimos dos laços sociais ou dos campos de significação do convívio comunicativo (a religião ou a magia, a produção e a troca de bens, o parentesco etc.) constituem conjuntos de relações submetidas a leis de transformação. A estrutura refere-se a elementos atômicos formais - que não possuem conteúdo, realidade, imagem, essência, significado, ou forma - dispostos em séries e combinações determináveis que explicariam tanto a constituição da totalidade do fenômeno quanto as possibilidades de variação entre os próprios elementos constituintes. ${ }^{4}$

Quando Lévi-Strauss interpreta o pensamento de Marcel Mauss no prefácio que escreve para sua obra, ele o faz a partir dos estudos dos lingüistas para os quais se tratava de "[...] distinguir um dado puramente fenomenológico, que a análise científica não pode determinar, de uma infra-estrutura mais simples do que ele, e à qual esse dado deve toda a sua realidade" (LÉVI-STRAUSS, 1950/1977, p. 173). Embora esse artigo seja dedicado justamente à tese de que Mauss fora, quanto a certos aspectos, um precursor da antropologia estrutural, nele surge um exemplo de como privilegiar a estrutura em detrimento do fenômeno quando o 
autor analisa os motivos pelos quais seu antecessor não teria seguido adiante em sua intuição original e renovadora da disciplina, impedindo-se de concretizar, de uma vez por todas, o projeto estrutural. O último desenvolvimento teórico do prefácio de Lévi-Strauss consiste em relacionar diretamente um dos mais antigos ensaios de Mauss, o Esquisse d'une théorie générale de la magie, ${ }^{5}$ de 1902, com alguns dos pilares da lingüística estrutural. Este ensaio está fundamentado na noção de mana, termo polinésio utilizado, segundo o prefaciador, a cada vez que se revela uma defasagem entre significante e significado. Para explicar-lhe o sentido, Mauss apela a sentimentos e crenças (categorias que, do ponto de vista de Lévi-Strauss, não podem ser explicativas pois pertencem à ordem do que deve ser explicado) quando, na verdade, seria necessário se referir à ordem de um sistema. Assim, o mana seria um tipo de resposta universal requerido sempre que a humanidade se encontra diante de uma situação específica:

\section{[...] estes tipos de noções intervêm, um pouco como símbolos algébricos, para representar um valor indeterminado de significação, em si mesmo desprovido de sentido, e, portanto, susceptível de receber seja que sentido for, cuja única função é preencher uma distância entre o significante e o significado ou, mais exatamente, assinalar o fato de que, em tal circunstância, em tal ocasião, ou em tal forma de manifestação, uma relação de inadequação se estabelece entre significante e significado [...] (LÉVI-STRAUSS, 1950/1977, p. 182-183, grifo nosso).}

Eis a crítica a Mauss: em seu próprio pensamento, o mana ocuparia o lugar de uma função mágica. Ele atribuiria ao pensamento indígena propriedades que pertenceriam, antes, à sua própria forma de pensar. Recorrer ao mana como explicação significa reduzir a antropologia à descrição da concepção que o próprio indígena faz de sua realidade, significa transformar uma disciplina que deveria ser científica numa "fenomenologia verbosa", numa "[...] mistura falsamente ingênua em que as obscuridades aparentes do pensamento indígena seriam alegadas para encobrir as confusões, de outro modo demasiado manifestas, do pensamento do etnólogo" (LÉVI-STRAUSS, 1950/1977, p. 184) .

A troca é o centro da questão. Para Lévi-Strauss, existe uma contradição que é própria ao pensamento simbólico, que define o domínio do social. Essa contradição consiste em que o símbolo nunca designa um referente, ele apenas remete a outros símbolos infinitamente; consiste em que o ser humano só é capaz de perceber as coisas por meio do crivo de sua relação com o outro, ou seja, mediante a comunicação já submetida à estrutura, da intersubjetividade, da linguagem, da troca, enfim; consiste na inexistência de uma continuidade entre simbólico e real, entre palavra e coisa. $\mathrm{O}$ autor explica:

A troca não é um edifício complexo, construído a partir das obrigações de dar, de receber e de restituir, à custa de um cimento afetivo e místico. É uma síntese imediatamente dada ao [e pelo] pensamento simbólico que, na troca, 
como em qualquer outra forma de comunicação, supera a contradição, que lhe é inerente, de perceber as coisas, assim como os elementos do diálogo, simultaneamente, através da relação de si com outrem, os quais estão destinados por natureza a passarem de um ao outro (LÉVI-STRAUSS, 1950/1977, p. 185).

Ou seja, o símbolo é aquilo que fundamenta a relação de si ao outro ao mesmo tempo em que passa de si ao outro. Dito ainda de outro modo, é a partir da estrutura de significantes que são "apreendidos" não apenas o ser próprio e o do outro, mas também os próprios significantes na mesma medida em que isso que é o fundamento circula entre os sujeitos envolvidos.

Assim, a noção de mana, no caso da magia, e a de hau, no caso do dom, que são da ordem do pensamento inconsciente, exercem a função de tamponar essa contradição, tornando possível o próprio funcionamento do sistema simbólico como um todo ao superar, de alguma forma, dois tipos de oposição: a oposição entre pensamento e realidade e a oposição entre o eu e o outro. Tais noções só podem ser compreendidas corretamente se essa sua função for vislumbrada, o que não teria ocorrido com as especulações de Mauss. O mana é "[...] a expressão consciente de uma função semântica, cujo papel é permitir ao pensamento simbólico exercer-se apesar da contradição que lhe é própria" (LÉVI-STRAUSS, 1950/1977, p. 188). E necessário ter sempre em conta o caráter relacional do pensamento simbólico, ou seja, o fato dele se afirmar como uma relação de troca. Assim, dizer que a função simbólica é o fator explicativo primordial significa dizer que a troca também o é. Esse raciocínio, Mauss não teria alcançado.

$*$

A forma como Lacan pensa a conformação do desejo na travessia do Édipo é absolutamente indissociável, ao lado de suas concepções sobre o acometimento do ser humano pelo registro imaginário, dessa idéia de estrutura (ora apenas indicada), acrescentando-lhe elementos decorrentes da especificidade do discurso psicanalítico: o Édipo transforma-se numa configuração transcendental necessária, articulada por dois significantes específicos - o Nome-do-Pai e o falo - detentora de relações dialéticas com a presença da imagem do corpo próprio e do semelhante e atualizada num drama efetivamente vivido. Por essa via, “(...) desde seu retorno a Freud [...], Lacan muda de galáxia conceitual sobre a questão do pai, e troca o pai de família - que constituía a solução de 1938 -, pela versão simbólica do pai cujo valor é tanto mais convincente na medida em que ele está morto" (ZAFIROPOULOS, 2003, p. 218-9). Morto justamente porque a instância de aplicação da Lei simbólica que caracteriza a instauração da necessidade de separação da mãe não admite encarnação possível: uma vez que qualquer sujeito sofre seu jugo, não pode sair de seu campo de incidência para promulgar-se seu enunciador. Este pai que instala o corte, para que fosse um pai vivo, teria que estar no (ou ser o) limite da função simbólica em vez de habitar a superfície de seu domínio, como ocorre com qualquer ser humano vivo. Se a universalidade do 
Édipo "é” a universalidade da função simbólica, então ele pode ser descrito como "esquema mínimo da experiência humana"6 que, como tal, descreve a constituição do posicionamento subjetivo diante do Outro: "Aquilo que está em jogo na análise não é outra coisa - reconhecer qual função assume o sujeito na ordem das relações simbólicas que cobre todo o campo das relações humanas e cuja célula inicial é o complexo de Édipo onde se decide a assunção do sexo" (LACAN, 1975, p. 80). É também de dentro da obra de Lévi-Strauss que essa relação íntima entre assunção do sexo e função simbólica pode ser vislumbrada: tanto as preferências sexuais quanto o uso da linguagem são funções de trocas reguladas pela estrutura inconsciente. Dessa perspectiva, o desejo sexual não pode ser anterior à entrada na linguagem pois ambos exigem a mesma ocorrência lógica da castração que, interpretada como separação irreversível efetuada pela palavra em relação à coisa ou como impedimento absoluto à imanência, é a operação capaz de responder pela diferença entre a condição humana e a condição animal. A lógica do inconsciente é a lógica combinatória das estruturas simbólicas e o que a psicanálise tem a fazer é encontrar os operadores conceituais que permitem entender como essa lógica se atualiza em uma posição desejante singular.

Tal tarefa recai, primeiramente sobre as condições em que se encontra um recém-nascido: sem dominar a linguagem e entregue à sorte que um outro lhe destina, seus vínculos pulsionais com a mãe são registrados sob o regime imaginário cujas diretrizes não distinguem amor e ódio numa tensão em que a afirmação de um eu implica a anulação do outro. Ocorre que esse outro, primeira figura do Outro, já se encontra, por sua vez, submetido à regulação simbólica prescritiva da metonímia do desejo. A mãe se direciona, em termos de libido, para outros alvos, alheios à criança, e, com isso, marca um movimento de presença/ausência - exemplificado paradigmaticamente no jogo do Fort-da. O que surge como símbolo desses outros alvos - ou como símbolo de que o desejo do outro (a mãe) é o desejo do Outro - é o falo, imagem sexualmente investida daquilo que falta a seu corpo e que se eleva à categoria de significante da presença do significante no Outro, ou seja, da presença de seu desejo: "[...] ele é esse significante que marca o que o Outro deseja na medida em que ele mesmo, como Outro real, Outro humano, é, em sua economia, marcado pelo significante" (LACAN, 1998, p. 366). Sendo o desejo a resultante, no corpo, do fracasso da linguagem em traduzir uma referência à realidade, o falo representa sua não conformação a qualquer objeto e sua eterna remissão ao desejo do Outro, isto é, à própria Lei inconsciente decretada pela estrutura que torna o desejo indissociável do significante. Ele é, assim, "[...] um símbolo geral dessa margem que sempre me separa de meu desejo e que faz com que meu desejo seja sempre marcado pela alteração que ele sofre por entrar no significante" (LACAN, 1998, p. 273).

Não fora esse olhar da mãe para além da criança, esta ficaria presa ao circuito imaginário no qual a fragilidade da linha de diferenciação eu-outro engendra fantasias revestidas do pavor da inexistência pela figura da devoração. A não-fixação na relação imaginária é a não assimilação da criança pela mãe ou o impedimento de que ela seja aprisionada numa posição de objeto, especificamente a do pênis que falta à imagem materna. É por isso que Lacan fala, seguindo pistas 
kleinianas, de uma anterioridade da castração materna (a castração paterna sendo um seu substituto ${ }^{7}$ ), cuja Lei seria mais cruel porquanto, nos termos de Safatle (2006, p. 118), sem transcendência: “[...] a Lei materna [...] não tem enunciação transcendente alguma, já que ela está totalmente ligada ao apetite da mãe. [...] Ela o faz entrar em um infinito ruim animado pela imaginarização impossível da falta materna". A castração paterna - na verdade, a única que carrega o sentido pleno da castração enquanto surgimento, para o sujeito, da ordem simbólica - "salva" a criança de uma não assunção à condição de sujeito porque, ao pôr em jogo o falo como significante, instaura a mediação de possibilidades dialéticas, combinatórias e metonímicas, próprias ao registro simbólico, de lidar com os limites do eu, com a presença da alteridade e com o posicionamento no lugar da enunciação. Lacan (1994-1995, p. 377), diz que a castração paterna:

[...] talvez, não seja menos terrível, mas é certamente mais favorável que a outra porque é suscetível de desenvolvimentos, o que não é o caso do engolimento e devoração pela mãe. Do lado do pai, um desenvolvimento dialético é possível. Uma rivalidade com o pai é possível, um assassinato do pai é possível, uma eviração do pai é possível. Por este lado, o complexo de castração é fecundo no Édipo, no lugar em que não o é pelo lado da mãe. E, por uma simples razão, é que é impossível emascular a mãe, de vez que ela não tem nada que se possa emascular.

Se é assim, o Nome-do-Pai metaforiza o Desejo-da-mãe ${ }^{8}$, não para impedir o desejo mas para fornecer as próprias condições de seu surgimento. Pois não há desejo sem essa elevação da necessidade à demanda através da fala que o produz como resto. Ao atravessar o Édipo, a criança assume o falo como significante de que o desejo (tanto o seu, quanto o da mãe) é desejo do Outro. Por isso, a castração que vem do pai afeta ambas: "Essa mensagem não é simplesmente o Não te deitarás com tua mãe, dirigido, já nessa época, à criança, mas um Não reintegrarás teu produto, dirigido à mãe" (LACAN, 1998, p. 202).

Interpretar a incidência do pai sobre a relação mãe-criança como a incidência da Lei simbólica passa, é claro, por uma identificação de ambos com a idéia de autoridade, como vemos na seguinte passagem: "É no nome do pai que devemos reconhecer o suporte da função simbólica que, desde o limiar dos tempos históricos, identifica sua pessoa com a figura da lei" (LACAN, 1953/1966, p. 278). Se a Lei é o que institui um corte em relação ao imaginário e é o pai que força, por sua presença e voz, um intervalo entre a mãe e a criança, então estão dados os elementos para uma leitura estrutural do Édipo pela convergência de ambas as tendências no significante Nome-do-Pai. A equação entre metáfora, figura paterna, lei e autoridade - no que segue, representada pelo "temor a Deus" - é o que justifica, para Lacan, a centralidade do Édipo para a psicanálise e para a experiência humana em geral:

Por que esse esquema mínimo da experiência humana que Freud nos deu no complexo de Édipo preserva para nós 
seu valor irredutível e, no entanto, enigmático? E por que esse privilégio do complexo de Édipo? Por que Freud quer sempre, com tanta insistência, reencontrá-lo por toda parte? Por que há aí um nó que lhe parece tão essencial que ele não o pode abandonar na menor observação particular? - se não é porque a noção do pai, muito próxima daquela de temor a Deus, lhe dá o elemento o mais sensível na experiência do que chamei o ponto de basta entre o significante e o significado (LACAN, 1981, p. 304).

A incidência do pai deve possuir uma dimensão empírica - ela não ocorre se sua fala não for valorizada pela mãe -, mas, no momento em que ocorre, se descola necessariamente da pessoa do pai ou de qualquer outra figura que tenha executado esse papel vinculado à lei, pois, a partir daí, ela se torna significante, Nome-do-Pai, indicando que o pai simbólico só pode ser um pai morto, inclusive para a instauração de um campo de visibilidade possível responsável pelas condições da presença do pai imaginário.

Para que o complexo de castração seja pelo sujeito verdadeiramente vivido, é preciso que o pai real jogue realmente o jogo. É preciso que ele assuma sua função de pai castrador, a função de pai sob sua forma concreta, empírica, diria quase degenerada [...] É na medida em que o pai, tal como existe, preenche sua função imaginária naquilo que esta tem de empiricamente intolerável, e mesmo de revoltante quando ele faz sentir sua incidência como castradora, e unicamente sob este ângulo - que o complexo de castração é vivido (LACAN, 1994-1995, p. 374).

Que o fato do Nome-do-Pai se inscrever ou não pertença, então, à ordem do acontecimento, dependendo do valor atribuído pela mãe à fala de um pai como presença e da execução empírica de um papel, isso parece indicar uma espécie de retorno da contingência sobre a estrutura, ou seja, que a resposta que o vivido apresenta face às orientações encetadas pelo arranjo significante na estrutura acaba construindo retroativamente uma forma de regulação sobre o sujeito, ainda que levemos em conta que tanto a mãe que assim se dirige ao pai quanto este, no preenchimento de sua função imaginária, estão, por sua vez, agindo conforme a posição que ocupam em relação aos significantes falo e Nome-do-Pai. Mesmo resguardado esse aspecto, é do lado empírico que chegam à criança certos elementos que servem de via de manifestação (seja pela ausência) de significantes logicamente necessários. Isso é interessante de ser observado na medida em que se configura necessariamente como matéria de tensão entre as funções a serem atribuídas, em termos de determinação, a procedimentos transcendentais e a eventos cujas origens residem nos fatos, ainda que também expostos a procedimentos transcendentais. 
Em todo caso, a inscrição do Nome-do-Pai transforma o Édipo em um mito a ser vivido. Interpretado estruturalmente, ele é como que um mito universal (que, no entanto, se expressa em termos individuais), uma vez que tudo o que pertence à ordem humana terá que se submeter a uma elaboração inconsciente do que significam e da forma como incidem no corpo os ganhos e as perdas decorrentes do uso compulsório da linguagem.

O falo e o Nome-do-Pai abrem, segundo esses termos, o campo de significação possível do desejo da mesma forma que o mana abria o campo de significação possível da magia e o hau abria o campo do dom para os indígenas, representando tanto a existência da contradição no nível da ordem simbólica - lembremo-la: que, apesar da inadequação de partida entre significante e significado, existem pontos de vinculação entre eles que tornam o sentido possível e circulável entre os sujeitos na mesma medida em que a própria relação intersubjetiva encontra-se estruturada pelos significantes -, quanto, por esse mesmo motivo, as condições de seu próprio funcionamento. Imbuídos de "valor simbólico zero" (LÉVI-STRAUSS, 1950/1977, p. 188), o que quer dizer, em última instância, símbolo da própria existência do símbolo -, na teoria psicanalítica lacaniana, o Nome-do-Pai é o nome do fato de haver nome, a metáfora que torna todas as outras possíveis, e o falo, sua contrapartida, ou seja, o nome das conseqüências disso no nível da implicação corpórea no caráter intersubjetivo do desejo. Opondo-se à ausência de significação ${ }^{9}$ que, no caso também seria ausência de desejo, sem implicarem, por si mesmos, nenhuma particularidade, eles são símbolos "no estado puro": ${ }^{10}$ valores puramente formais que só se vinculam ao empírico por suas contrapartidas imaginárias. Zafiropoulos também estabelece essa correlação entre a teoria lacaniana do Édipo e o "significante flutuante" em Lévi-Strauss (1950/1977, p. 188), mas o faz apenas com respeito ao Nome-do-Pai, ao dizer, por exemplo, que: "A assinalação do valor lingüístico e inconsciente do 'significante flutuante' que permite ao pensamento simbólico exercer-se, é - a nosso ver - uma elegante definição daquilo que Lacan desdobrará a partir de $1953 \mathrm{sob}$ a noção de nome do pai" (ZAFIROPOULOS, 2003, p. 181). Elementos próprios à escuta psicanalítica (o símbolo fálico) e o valor da idéia de que o desejo não é de objeto mas do desejo do Outro exigem, a nosso ver, o emparelhamento do Nome-do-Pai com o falo na distribuição da mesma função sob dois ângulos diferenciados. Essa sua caracterização era, de resto, assinalada por Deleuze. Após emparelhar tanto o mana e seus equivalentes quanto o falo ao "objeto $=\mathrm{x}$ " ou casa vazia, ele afirma:

Pai, mãe, etc. são elementos simbólicos tomados em relações diferenciais, mas o falo é outra coisa, o objeto $=\mathrm{x}$ que determina o lugar relativo dos elementos e o valor variável das relações fazendo de toda a sexualidade uma estrutura. É em função dos deslocamentos do objeto $=\mathrm{x}$ que as relações variam, como relações entre 'pulsões parciais' constitutivas da sexualidade. (DELEUZE, 1972/1981, p. 296) 
Com esse percurso, podemos agora entender uma proposição que bem ilumina o conjunto dessa discussão: "Trata-se assim da negação de uma determinação empírica que nos leva a uma transcendência que se conserva no interior de um princípio transcendental formalizado por um significante puro" (SAFATLE, 2006, p. 133). O desejo, descolado de uma conformação empírica e relacionado em seu cerne a uma falta que não pode ser recoberta por uma imagem, é, essencialmente, o movimento de transcender a si mesmo pela negação das coisas, dirigindo-se para o fora que é o desejo do Outro, e o que regula tal movimento é um plano transcendental: a estrutura cujo funcionamento, por um lado, impõe uma regência precisa dos elementos simbólicos em suas combinações e alterações e, por outro, secreta significantes em estado puro que dizem de seu limite e de sua condição. É isso o que explica o caráter vazio da Lei do pai ${ }^{11}$ : ela diz respeito a esse campo formalizado que, guardando a verdade do sujeito ao responder por sua posição (de desejo) diante do Outro, é responsável pela constituição das fixações de objeto imaginárias que, por sua vez, se antepõem ao alcance dessa verdade. Se a linguagem é sempre incapaz de fornecer representações "adequadas" do que quer que seja, atualizando sempre o fracasso de uma suposta referência, e, se o desejo é definido por uma operação de negação - pela qual, aliás, ele se identifica mesmo à linguagem -, então o falo, valor simbólico zero, não pode ser outra coisa senão a colocação em significante da impossibilidade de que o pênis, ou qualquer outro objeto que se apresente na condição de conteúdo representacional, viesse a fornecer esteio imaginário à sexualidade. Por isso, ele é tanto mais significativo quanto mais ausente ${ }^{12}$; ele é "[...] apenas a inscrição significante da impossibilidade de uma representação adequada do sexual no interior da ordem simbólica. Ele é a inscrição significante da relação de inadequação entre o sexual e a representação" (SAFATLE, 2006, p. 130). Para Lacan, existe uma discordância fundamental inerente ao desejo sexual que lhe atribui um caráter essencialmente problemático. Trata-se aí de um desdobramento do conflito entre subjetividade e objetividade, pois, localizando-se em um lugar que ultrapassa a demanda de amor (processo que tenderia a preservar a dimensão da alteridade), o desejo sexual exige que um outro sujeito seja compelido a uma posição de objeto:

[...] há discordância entre o que existe de absoluto na subjetividade do Outro que dá ou não dá o amor e o fato de que, para que haja acesso a ele como objeto de desejo, é necessário que ele se faça totalmente objeto. É nesse desvio vertiginoso - nauseante, para chamá-lo por seu nome - que se situa a dificuldade de acesso na abordagem do desejo sexual (LACAN, 1998, p. 384).

Noutras palavras, o desejo sexual comporta a relação com a imagem do Outro, imagem que o significante (ou a lógica simbólica que é a lógica do próprio desejo) nega e que, pelas tensões existentes na dinâmica imaginária, significa, a uma só vez, a própria anulação da alteridade. Se o próprio Outro aparece então como "instrumento" do desejo, o que temos aí é uma complicação ou uma reduplicação dos paradoxos constitutivos da função de nomeação que tem nele mesmo sua origem (no Outro ou na estrutura cuja subjetivação ele expressa). O desejo 
sexual aparece como pergunta dirigida a um Outro impulsionado à destituição de suas prerrogativas de sujeito ao mesmo tempo em que qualquer possibilidade de nomeação desse desejo só poderia partir desse lugar que, com ele, "tende a ser" negado. É nesse contexto que Lacan afirma: “[...] nem tudo é redutível à linguagem. [...] não existe palavra para exprimir uma coisa, uma coisa que tem um nome e que é justamente o desejo.” (LACAN, 1998, p. 383)

Assim, apesar de aparecer na escuta clínica com uma recorrência que reclama trato teórico, a justificação do lugar do falo na economia do desejo é de ordem lógica:

É por razões inscritas na ordem simbólica, transcendendo o desenvolvimento individual, que o fato de ter ou não o falo imaginário e simbolizado assume a importância econômica que tem no nível do Édipo. Isso é o que motiva ao mesmo tempo a importância do complexo de castração e a preeminência das famosas fantasias da mãe fálica [...] (LACAN, 1956-57/1994, p. 195, grifo nosso).

Agora sabemos a quais marcos conceituais essas razões são atribuídas: o funcionamento da estrutura, tal como concebido por Lévi-Strauss e aplicado à psicanálise abre um lugar para o falo, ao lado do Nome-do-Pai, no preenchimento da função do valor simbólico zero: eles respondem pela atualização simbólica, na estrutura, da própria existência da estrutura, permanecendo, nesse sentido, no limite do campo da linguagem na mesma medida em que representam ou operacionalizam o limite por ela própria imposto.

\section{Notas}

1 Ver LACAN, 1938, p. 8'40-15.

2 Ver LÉVI-STRAUSS, 1949a/1975, 1949b/1975, 1950/1977, 1955/1975; SIMANKE, 2002, p. 431-523 e SALES, 2003.

3 Ver LÉVI-STRAUSS, 1947/1976.

${ }^{4}$ Cf. DELEUZE, 1972/1981.

5 Escrito na companhia de Henri Hubert.

6 Por discordar dessa identificação, não obstante explicitada por Lacan (por exemplo, nesta última expressão citada), Zafiropoulos (2003, p. 56-57) não pensa que a estrutura universalize o Édipo, defendendo que ele é apenas uma das modulações possíveis, culturalmente determinadas, da função do mito, essa sim, universal: "Se Lacan [...] invoca a fala do pai morto e a exigência do simbólico, ele indica que a organização descrita por Freud [o complexo de Édipo] é apenas um caso de um sistema muito mais vasto, e que é menos necessário procurar a universalidade do complexo e de sua forma do que a da função simbólica e de sua ordem”. Ou, adiante: “[...] não se trata mais aqui destacar, de acordo com os termos de 1950, as 'condições sociais do Édipo' [...], mas tratar-se-ia de perceber a forma como a evolução social reduz a proibição do incesto às modestas dimensões do drama edipiano" (ZAFIROPOULOS, 2003, p. 168).

7 Ver LACAN, 1994/1995, p. 377.

8 V. a metáfora paterna em LACAN, 1959/1966, p. 557.

9 Por analogia com o fonema zero, desenvolvido por Jakobson como o fonema que se opõe à ausência de fonema, Lévi-Strauss afirma: “[...] a função das noções de tipo mana é a de se opor à ausência de significação sem comportar por si mesma nenhuma significação particular" (1950/1977, p. 189).

10 "Assim se explicam as antinomias, na aparência insolúveis, ligadas a esta noção, que tanto impressionaram os etnógrafos e que Mauss pôs a claro: força e ação; qualidade e estado; 
substantivo, adjetivo e verbo ao mesmo tempo; abstrato e concreto, onipresente e localizado. E, com efeito, o mana é tudo isto ao mesmo tempo; mas não será ele tudo isso precisamente por não ser nada disso: simples forma, ou, mais exatamente, símbolo no estado puro, portanto suscetível de se carregar de qualquer conteúdo simbólico, seja ele qual for?" (LÉVI-STRAUSS, 1950/1977, p. 188).

${ }^{11}$ Ver SAFATLE, 2006, p. 119.

12 "O fato de o falo ser mais significativo na vivência humana por sua possibilidade de ser um objeto decaído do que por sua presença, é isso que aponta a possibilidade do lugar da castração na história do desejo" (LACAN, 2004-2005, p. 187).

\section{REFERÊNCIAS}

DELEUZE, G. Em que se pode reconhecer o estruturalismo? (1972). In: CHÂTELET, F. (Org.). História da filosofia: idéias, doutrinas - Volume 8: O século XX. Tradução de Hilton Japiassú. Rio de Janeiro: J. Zahar, 1981.

LACAN, J. La famille. In: . La vie mentale. Paris: Larousse, 1938. Encyclopédie Française, v. VIII, p. 8’ $40-3$ - 8’42-8.

. Fonction et champ de la parole et du langage en psychanalyse (1953). In: Écrits. Paris: Seuil, 1966. p. 237-322.

.Le Séminaire: les éscrits techniques de Freud (1953-1954). Paris: Éditions du Seuil, 1975. Livre I.

. Le Séminaire: les psychoses (1955-1956). Paris: Seuil, 1981. Livre III.

. O Seminário: a relação de objeto (1956-1957). Tradução de Dulce Duque

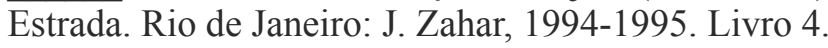

. Le Séminaire: les formations de l'inconscient (1957-1958). Paris: Seuil, 1998. Livre V.

. D'une question préliminaire à tout traitement possible de la psychose (1959). In: . Écrits. Paris: Seuil, 1966. p. 531-583.

. O Seminário: a angústia (1962-1963). Tradução de Dulce Duque Estrada. Rio de Janeiro: J. Zahar, 2004-2005. Livro 10.

LÉVI-STRAUSS, C. As estruturas elementares do parentesco (1947). Tradução de Mariano Ferreira. Petrópolis: Vozes; São Paulo: Universidade de São Paulo, 1976.

. O feiticeiro e sua magia (1949a). In: . Antropologia estrutural. Tradução de Chaim Samuel Katz e Eginardo Pires. Rio de Janeiro: Tempo Brasileiro, 1975. p. 193-213. 
LÉVI-STRAUSS, C. A eficácia simbólica (1949b). In: Antropologia estrutural. Tradução de Chaim Samuel Katz e Eginardo Pires. Rio de Janeiro: Tempo Brasileiro, 1975. p. 215-236.

. Introdução à obra de Marcel Mauss (1950). In: COELHO, E. P. (Org.). Estruturalismo: antologia de textos teóricos. Tradução de Maria Eduarda Reis Colares, António Ramos Rosa, Eduardo Prado Coelho. São Paulo: Martins Fontes, 1977. p. 149-190.

A estrutura dos mitos (1955). In: . Antropologia estrutural I. Tradução de Chaim Samuel Katz, Eginardo Pires. Rio de Janeiro: Tempo Brasileiro, 1975. p. 237-265.

SAFATLE, V. P. A paixão do negativo: Lacan e a dialética. São Paulo: UNESP, 2006.

SALES, L. S. O valor epistemológico do diálogo de Jacques Lacan com o estruturalismo. Revista Psychê. São Paulo, v. 11, p. 39-58, jun. 2003.

SIMANKE, R. T. Metapsicologia lacaniana: os anos de formação. São Paulo: Discurso; Curitiba: UFPR, 2002.

ZAFIROPOULOS, M. Lacan et Lévi-Strauss: ou le retour à Freud (1951-1957). Paris: PUF, 2003.

Recebido em: junho de 2007

Aceito em: fevereiro de 2008 